\title{
BIOMASSA MICROBIANA DO SOLO EM SISTEMA DE INTEGRAÇÃO LAVOURA-PECUÁRIA EM PLANTIO DIRETO, SUBMETIDO A INTENSIDADES DE PASTEJO(1)
}

\author{
Edicarlos Damacena de Souza ${ }^{(2)}$, Sérgio Ely Valadão Gigante de Andrade \\ Costa $^{(3)}$, Ibanor Anghinoni ${ }^{(4)}$, Christina Venzke Simões de Lima ${ }^{(5)}$, Paulo \\ César de Faccio Carvalho ${ }^{(7)} \&$ Amanda Posselt Martins ${ }^{(6)}$
}

\begin{abstract}
RESUMO
Em sistemas de integração lavoura-pecuária, boa parte do suprimento de nutrientes para as pastagens provém das excreções dos animais, na forma de esterco e de urina, o que resulta em estímulo à atividade e ao acúmulo de nutrientes nas suas células. Este estudo foi desenvolvido num experimento de integração lavourapecuária em plantio direto, iniciado em 2001, e objetivou avaliar o impacto de diferentes intensidades de pastejo da pastagem de inverno (aveia-preta + azevém; 10,20 e $40 \mathrm{~cm}$, e um tratamento sem pastejo) sobre a atividade microbiana e sobre os teores e estoques de $\mathrm{C}, \mathrm{N}$ e $\mathrm{P}$ na biomassa microbiana na camada de $\mathbf{0}-10 \mathrm{~cm}$ de um Latossolo Vermelho, no Sul do Brasil, durante o ciclo da pastagem. Os teores e estoques dos nutrientes na biomassa e a atividade microbiana foram alterados pela intensidade de pastejo e pela época no ciclo da pastagem. Os teores de $\mathrm{C}$ e de $P$ microbiano aumentaram do início da pastagem, em maio, até o período de grande produção de fitomassa, em setembro, após o qual decresceram, acompanhando o início de senescência da pastagem. Por sua vez, o $\mathrm{N}$ microbiano decresceu de maio para novembro, possivelmente devido à absorção desse nutriente pelas plantas. Sistemas de integração lavoura-pecuária em plantio direto mantêm a qualidade
\end{abstract}

\footnotetext{
(1) Parte da pesquisa de Tese de Doutorado do primeiro autor apresentada ao Programa de Pós-Graduação em Ciência do Solo da Universidade Federal do Rio Grande do Sul - UFRGS. Trabalho financiado com recursos da Fundação Agrisus e CNPq. Recebido para publicação em outubro de 2008 e aprovado em novembro de 2009.

(2) Pós-Doutorando do Programa de Pós-Graduação em Agronomia, Universidade Federal de Goiás - Campus de Jataí (GO). Email: edidamacena2000@yahoo.com.br

(3) Mestre em Ciência do Solo, Universidade Federal do Rio Grande do Sul - UFRGS. Av. Bento Gonçalves, 7712, CEP 91540000 Porto Alegre (RS). E-mail: sergioelycosta@hotmail.com

(4) Professor do Departamento de Solos, UFRGS. Bolsista do CNPq. E-mail: ibanghi@ufrgs.br

(5) Doutoranda em Ciência do Solo, UFRGS. E-mail: chris.solos@yahoo.com.br

(6) Professor de Departamento de Plantas Forrageiras e Agrometeorologia, UFRGS. Bolsista do CNPq. E-mail: paulocfc@ufrgs.br

(7) Graduanda em Agronomia, UFRGS. E-mail: amandaposselt@gmail.com
} 


\begin{abstract}
biológica do solo, sendo, sob adequada lotação animal, similar ao sistema plantio direto sem a entrada de animais. No entanto, sob alta intensidade de pastejo $(10 \mathrm{~cm})$ há perdas nessa qualidade do solo em condições de estresse hídrico.
\end{abstract}

Termos de indexação: quociente metabólico, nitrogênio microbiano, fósforo microbiano.

\title{
SUMMARY: SOIL MICROBIAL BIOMASS IN A NO-TILLAGE INTEGRATED CROP-LIVESTOCK SYSTEM UNDER DIFFERENT GRAZING INTENSITIES
}

\begin{abstract}
In integrated crop-livestock systems most of the nutrient supply for a pasture is provided by animal excretions, in the form of manure or urine, stimulating the activity and accumulation of nutrients in the cells. This study was carried out in an integrated crop-livestock system under no-tillage, initiated in 2001, with the objective of evaluating the impact of different winter grazing intensities (black oat + Italian ryegrass; 10, 20, and $40 \mathrm{~cm}$, and a no-grazing control treatment) on microbial activity and on carbon, nitrogen and phosphorus concentration and stocks in microbial biomass in the 0-10 cm layer of an Oxisol (Latosol), in southern Brazil, during a grazing cycle. Biomass nutrient contents and stocks and microbial activity were affected by grazing intensities and by the season of the grazing cycle. Microbial carbon and phosphorus contents increased in the beginning of the grazing cycle in May until the period of high phytomass production in September, after which these contents decreased, following the pasture senescence. On the other hand, microbial nitrogen decreased from May to November, possibly as a result of plant uptake of soil N. Integrated crop-livestock systems under notillage maintain soil biological quality, and are, under adequate grazing intensity, similar to no-tillage systems without grazing influence. However, at high grazing intensities $(10 \mathrm{~cm})$ under water stress, this soil quality is negatively affected.
\end{abstract}

Index terms: Metabolic quotient, microbial nitrogen, microbial phosphorus.

\section{INTRODUÇÃO}

A biomassa microbiana do solo (BMS) é a fração viva da matéria orgânica, responsável por processos bioquímicos e biológicos no solo e sensivelmente alterada pelas condições impostas pelo meio (Balota et al., 2008). Dessa forma, a BMS é influenciada pelo clima, pela aeração, pela disponibilidade de nutrientes minerais e pelo C orgânico do solo. Em situações com maior deposição de resíduos orgânicos no solo e com grande quantidade de raízes, há estímulo da biomassa microbiana, acarretando seu aumento populacional e de sua atividade (Cattelan \& Vidor, 1990). A biomassa microbiana também representa o compartimento central do ciclo do C, do N, do P e do S no solo e pode funcionar como compartimento de reserva desses nutrientes ou como catalisador na decomposição da matéria orgânica. Assim, além dos fatores de ambiente, a quantidade e a qualidade dos resíduos vegetais depositados sobre o solo podem alterar consideravelmente a atividade e a BMS.

Em sistemas de integração lavoura-pecuária, as excreções dos animais, na forma de esterco e de urina, irão influenciar a dinâmica do C orgânico no solo, que passa a ser o suprimento mais importante de nutrientes para as pastagens (Haynes \& Williams, 1999). O acúmulo desse material no solo implicará aumento da matéria orgânica, com consequente estímulo à BMS (Rezende et al., 2004). Além disso, em sistemas de manejo do solo em que são incluídas gramíneas para pastejo ocorre maior presença de raízes, que promovem aumento na proporção de solo rizosférico. Quanto maior a quantidade dessas raízes, aliado ao corte da parte aérea, que provoca alta exsudação de compostos orgânicos (Tisdall \& Oades, 1982), maior é o favorecimento da BMS, que utiliza esses compostos como fonte de C. Nesses sistemas de manejo ocorre adição de resíduos tanto vegetais como animais. Os resíduos vegetais são provenientes da cultura de interesse comercial e da pastagem, cujo maior ou menor aporte será em função da intensidade de pastejo adotada.

Em menores intensidades de pastejo ocorre também adição significativa de resíduos pela parte aérea das plantas; já na maior intensidade há maior adição de resíduos provenientes dos dejetos animais, alterando, dessa forma, negativamente a labilidade da matéria orgânica (Souza, 2008). Com diferentes labilidades da matéria orgânica, a BMS tende a se comportar de maneira distinta entre as intensidades de pastejo, pois 
ela utiliza principalmente essa fração como fonte de C e de energia para sua manutenção, alterando tanto os teores de nutrientes em suas células como sua atividade (Souza et al., 2006a,b). Além disso, o estádio de desenvolvimento da pastagem e a inserção ou não dos animais podem alterar a BMS, pois esta é muito sensível a mudanças, mesmo que pequenas, no manejo do solo, por ser a fração viva da matéria orgânica (Conceição et al., 2005; Souza et al., 2006a,b, 2008). Com isso, espera-se que o aumento na intensidade de pastejo diminua a população e a atividade microbiana do solo, devido ao menor suprimento de resíduos vegetais; espera-se também variação da BMS de acordo com o estádio de desenvolvimento da pastagem, em razão da quantidade e qualidade de resíduos disponíveis e das condições de clima, e, ainda, que os teores de $\mathrm{N}$ e de $\mathrm{P}$ no tecido microbiano variem com a época de amostragem e com os teores desses nutrientes disponíveis no solo.

Assim, objetivou-se avaliar o impacto de diferentes intensidades de pastejo, no inverno, sobre os teores de $\mathrm{C}$, de $\mathrm{N}$ e de $\mathrm{P}$ da biomassa microbiana e sua atividade no solo ao longo do ciclo de pastejo em um sistema de integração lavoura-pecuária em plantio direto no Sul do Brasil.

\section{MATERIAL E MÉTODOS}

O estudo foi realizado em área experimental localizada na fazenda do Espinilho, pertencente à Cabanha Cerro Coroado, cuja sede está localizada no município de São Miguel das Missões, na região fisiográfica do Planalto Médio - RS, Sul do Brasil. O experimento vem sendo conduzido, desde maio de 2001, em um Latossolo Vermelho distroférrico (Embrapa, 2006) profundo bem drenado com coloração vermelhoescura e textura argilosa $\left(0,54 \mathrm{~kg} \mathrm{~kg}^{-1}\right.$ de argila,
$0,27 \mathrm{~kg} \mathrm{~kg}^{-1}$ de silte e $0,19 \mathrm{~kg} \mathrm{~kg}^{-1}$ de areia). Antes do início do experimento, a área foi cultivada em sistema plantio direto por 10 anos com aveia-preta (Avena strigosa Schreb), para a produção de sementes no inverno, e soja (Glycine max), para grãos no verão. Antes da implantação do primeiro ciclo da cultura da soja, em novembro de 2001, foi feita uma aplicação superficial de calcário em toda a área, na dosagem de 4,5 Mg ha-1 (PRNT de $62 \%$ ), recomendada para elevar o $\mathrm{pH}$ do solo até 5,5 para o sistema plantio direto consolidado (CQFSRS/SC, 2004).

No outono de 2001 e nos anos subsequentes a pastagem era implantada em plantio direto, após a colheita da soja; ela era composta por aveia-preta (100 kg ha ${ }^{-1}$ de sementes) e azevém (Lolium multiflorum Lam.), cuja população era originária em parte da ressemeadura natural, em parte do plantio de sementes $\left(30 \mathrm{~kg} \mathrm{ha}^{-1}\right)$. A área total do experimento é de 22 ha, a qual foi dividida em 12 parcelas experimentais (potreiros), cujos tamanhos variam de 1,0 a 2,5 ha, em função dos tratamentos aplicados.

Os tratamentos constaram de três intensidades de pastejo, reguladas a partir da altura da pastagem $(10$, 20 e $40 \mathrm{~cm}$ ), distribuídas num delineamento experimental de blocos ao acaso, com três repetições, sendo a altura da pastagem acompanhada a cada 14 dias, pelo método Sward stick (Bircham, 1981). O método de pastejo adotado foi o pastejo contínuo, de modo que as alturas de manejo da pastagem foram obtidas pela variação de carga, retirando-se animais das parcelas quando a altura real era menor que a pretendida e vice-versa. Nas áreas entre os blocos o pastejo foi excluído, sendo elas consideradas como de referência (sem pastejo). A fim de auxiliar a interpretação dos resultados de biomassa microbiana, os atributos físicos do solo, relacionados à matéria orgânica do solo e produtividade de soja, são apresentados no quadro 1 , e a matéria seca aérea da pastagem nas diferentes intensidades de pastejo, no quadro 2 .

Quadro 1. Atributos físicos, carbono orgânico total, carbono na materia orgânica particulada, nitrogênio total e nitrogênio na matéria orgânica particulada, na camada de 0 a $10 \mathrm{~cm}$, e matéria seca da parte aérea e produtividade da soja em um Latossolo Vermelho distroférrico em sistema de integração lavourapecuária submetido a intensidades de pastejo em plantio direto (maio/2007)

\begin{tabular}{|c|c|c|c|c|c|c|c|c|c|c|c|c|}
\hline $\begin{array}{c}\text { Intensidade } \\
\text { de pastejo }\end{array}$ & Ds & VTP & Ma & Mi & COT & COP & COP/COT & NT & $\begin{array}{c}\text { N- } \\
\text { MOP }\end{array}$ & $\begin{array}{c}\text { N- } \\
\text { MOP/NT }\end{array}$ & MS & PROD \\
\hline & $\mathrm{kg} \mathrm{dm}^{-3}$ & 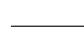 & $\mathrm{m}^{3} \mathrm{~m}^{-3}$ & - & \multicolumn{2}{|c|}{ - $\mathrm{g} \mathrm{kg}^{-1}-$} & $\%$ & \multicolumn{2}{|c|}{$\ldots \mathrm{g} \mathrm{kg}^{-1} \_$} & $\%$ & \multicolumn{2}{|c|}{ — $\mathrm{kg} \mathrm{ha}^{-1} \_$} \\
\hline P-10 & 1,37 & 0,51 & 0,07 & 0,44 & 24,0 & 3,1 & 12,9 & 2,1 & 0,26 & 12,4 & 5.590 & 3.546 \\
\hline P-20 & 1,31 & 0,54 & 0,09 & 0,45 & 27,1 & 4,1 & 15,1 & 2,3 & 0,37 & 16,1 & 5.970 & 3.525 \\
\hline P- 40 & 1,32 & 0,53 & 0,09 & 0,44 & 26,3 & 4,1 & 15,6 & 2,3 & 0,35 & 15,2 & 5.330 & 3.743 \\
\hline SP & 1,31 & 0,55 & 0,11 & 0,44 & 26,9 & 4,8 & 17,8 & 2,4 & 0,36 & 15,2 & 5.660 & 3.706 \\
\hline
\end{tabular}

Ds: densidade do solo; VTP: volume total de poros; Ma: macroporosidade; Mi: microporosidade; COT: carbono orgânico total; COP: carbono orgânico particulado; NT- nitrogênio total; N-MOP: nitrogênio na matéria orgânica particulada; MS: matéria seca da parte aérea da soja; PROD: produtividade da soja. P-10, P-20, P-40 e SP representam as alturas de pastejo de 10 , 20 e 40 cm e sem pastejo, respectivamente. 
Quadro 2. Matéria seca da parte aérea (mantilho + parte aérea de plantas) em um Latossolo Vermelho distroférrico em sistema de integração lavoura-pecuária submetido a intensidades de pastejo em plantio direto

\begin{tabular}{ccrcr}
$\begin{array}{c}\text { Intensidade } \\
\text { de pastejo }\end{array}$ & Julho & Setembro & Novembro & Média \\
& & \multicolumn{4}{c}{$\mathrm{kg} \mathrm{ha}^{-1}$} \\
\cline { 2 - 5 } & & & \\
P-10 & $1.225 \mathrm{aA}$ & $834 \mathrm{cA}$ & $485 \mathrm{dA}$ & 848 \\
P-20 & $1.172 \mathrm{aB}$ & $2.281 \mathrm{bA}$ & $1.940 \mathrm{cAB}$ & 1.797 \\
P-40 & $1.501 \mathrm{aC}$ & $5.133 \mathrm{aA}$ & $3.459 \mathrm{bB}$ & 3.364 \\
SP & $1.350 \mathrm{aB}$ & $4.957 \mathrm{aA}$ & $5.892 \mathrm{aA}$ & 5.425 \\
Média & 1.312 & 3.301 & 2.944 & -
\end{tabular}

P-10, P-20, P-40 e SP representam as alturas de pastejo de 10, 20 e $40 \mathrm{~cm}$ e sem pastejo, respectivamente. Letras minúsculas na coluna comparam os tratamentos dentro de cada época. Letras maiúsculas comparam as épocas dentro de cada tratamento. Letras semelhantes não diferem entre si pelo teste de Tukey a $5 \%$.

Após a retirada dos animais em 13/11/2006 (ano anterior às avaliações deste trabalho), a pastagem foi dessecada para que fosse realizada a semeadura da soja, que ocorreu no dia 4/12/2006 em plantio direto, sendo os tratos culturais os recomendados para a cultura. A cultivar utilizada foi a Iguaçu, sendo semeada via plantio direto, num espaçamento entre linhas de $45 \mathrm{~cm}$. A adubação de base, em função da análise do solo e expectativa de produtividade, foi constituída da aplicação de $300 \mathrm{~kg} \mathrm{ha}^{-1}$ da fórmula 00 20-30. O histórico de cultivo e adubação do experimento pode ser encontrado em Souza (2008). A precipitação pluvial no ano de 2007 é apresentada na figura 1. A colheita da soja foi realizada em 28/04/ 2007. Para esse ano, a semeadura da aveia e azevém foi efetuada em 30/04 e a aplicação de N (90 kg ha-1

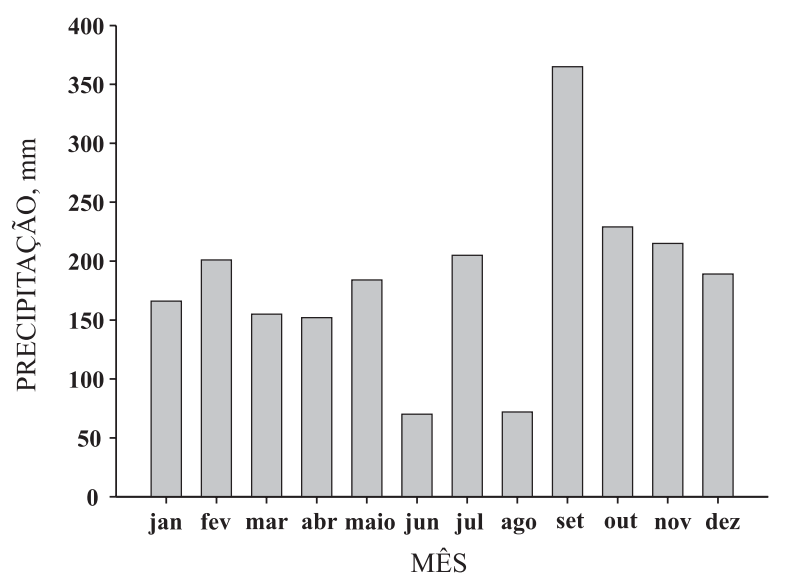

Figura 1. Precipitação pluvial no ano de 2007 na fazenda do Espinilho, em São Miguel das Missões/ RS. de $\mathrm{N}$, na forma de ureia) em cobertura, após 45 dias (14/06). A pastagem foi utilizada por bovinos machos, com idade em torno de 12 meses e peso vivo inicial de aproximadamente $200 \mathrm{~kg}$. Os animais iniciaram o pastejo quando o pasto tinha acumulado por volta de $1.000 \mathrm{~kg} \mathrm{ha}^{-1}$ de matéria seca, o que ocorreu em 14/ 07/2007, permanecendo em pastejo até 15/11/2007 (125 dias).

As determinações relacionadas à biomassa microbiana foram realizadas em amostras de solo coletadas nas seguintes épocas: logo após a colheita da soja (maio/2007); no início do pastejo pelo gado (julho/2007); no meio do ciclo de pastejo (setembro/ 2007); e no final do ciclo de pastejo (novembro/2007). As amostras foram coletadas na camada de 0 a $10 \mathrm{~cm}$, em oito pontos por parcela, formando uma amostra composta e representativa de cada tratamento. As amostras foram acondicionadas em caixa térmica para o transporte até o Laboratório de Fertilidade do Solo do Departamento de Solos da UFRGS, onde foram armazenadas em refrigerador $\left(4^{\circ} \mathrm{C}\right)$, por no máximo cinco dias. Um dia antes da realização das análises, as amostras foram retiradas do refrigerador e deixadas em temperatura ambiente por $24 \mathrm{~h}$; em seguida, foram retiradas as raízes, e o solo, passado em peneira de $2 \mathrm{~mm}$ de abertura. No momento da retirada das amostras do refrigerador, foi avaliada a umidade em subamostra de solo, a qual foi pesada e seca a $105^{\circ} \mathrm{C}$ em estufa por $24 \mathrm{~h}$; posteriormente, pesou-se a amostra de solo seco (Quadro 3).

$\mathrm{O} \mathrm{C}$ e $\mathrm{N}$ da biomassa microbiana foram obtidos pelo método da irradiação-extração (Mendonça \& Matos, 2005), o qual consiste no uso de energia eletromagnética (micro-ondas), causando efeito na transferência de energia e temperatura, levando a um rompimento celular com liberação dos compostos intracelulares. Segundo o método proposto por Islam \& Weil (1998), a energia necessária para provocar a lise bacteriana é de $800 \mathrm{~J} \mathrm{~s}^{-1} \mathrm{~g}^{-1}$ solo em base seca. Para isso, aqueles autores sugerem a fórmula para

Quadro 3. Umidade gravimétrica, na camada de 0 a $10 \mathrm{~cm}$, em um Latossolo Vermelho distroférrico em sistema de integração lavoura-pecuária submetido a intensidades de pastejo em plantio direto

\begin{tabular}{ccccc}
\hline $\begin{array}{c}\text { Intensidade } \\
\text { de pastejo }\end{array}$ & Maio & Julho & Setembro & Novembro \\
\hline & \multicolumn{4}{c}{$\mathrm{kg} \mathrm{kg}^{-1}$} \\
P-10 & 0,21 & 0,26 & 0,17 & 0,26 \\
P-20 & 0,21 & 0,26 & 0,23 & 0,27 \\
P-40 & 0,21 & 0,26 & 0,24 & 0,27 \\
SP & 0,22 & 0,26 & 0,23 & 0,27
\end{tabular}

P-10, P-20, P-40 e SP representam as alturas de pastejo de 10, 20 e $40 \mathrm{~cm}$ e sem pastejo, respectivamente. 
cálculo do tempo de irradiação, que é T = RW/P, em que T é o tempo de irradiação (s); R, a energia incidente pretendida sobre a amostra; $\mathrm{W}$, a massa de solo (base seca); e P, a potência do micro-ondas. Contudo, os autores enfatizam que a temperatura da massa de solo úmido deve ficar acima de $80{ }^{\circ} \mathrm{C}$, e não deve ultrapassar $88^{\circ} \mathrm{C}$ para não provocar a liberação de $\mathrm{C}$ não microbiano durante a irradiação. Antes da realização da extração, a calibração do aparelho de micro-ondas foi feita utilizando um volume conhecido de água e, em seguida, foi preestabelecido o tempo de irradiação para a elevação da temperatura no interior do micro-ondas.

Posteriormente, a extração foi realizada com sulfato de potássio $0,5 \mathrm{~mol} \mathrm{~L}^{-1}$; a oxidação, com dicromato de potássio $0,066 \mathrm{~mol} \mathrm{~L}^{-1}$; e a titulação, com sulfato ferroso amoniacal $0,033 \mathrm{~mol} \mathrm{~L}^{-1}$. A respiração microbiana foi estimada pelo $\mathrm{CO}_{2}$ evoluído a partir de $20 \mathrm{~g}$ de solo durante $72 \mathrm{~h}$, com extração por $\mathrm{NaOH}$ $0,05 \mathrm{~mol} \mathrm{~L}^{-1}$ e titulação com $\mathrm{HCl}$ 0,05 mol L-1 (Alef \& Nannipieri, 1995). O quociente metabólico foi determinado pela relação entre a respiração e a biomassa microbiana (Anderson \& Domsh, 1993). O $\mathrm{N}$ da biomassa microbiana foi determinado no mesmo extrato em que foi determinado o $\mathrm{C}$ da biomassa microbiana, e a determinação foi efetivada segundo Tedesco et al. (1995). Os estoques de C e $\mathrm{N}$ na biomassa microbiana foram calculados com base no método da massa equivalente de solo (Ellert \& Bettany, 1995), utilizando para isso as densidades de solo apresentadas em Conte (2007), tendo como referência a massa de solo da área sem pastejo.

Avaliou-se o conteúdo de P na biomassa microbiana pelo método da irradiação-extração (Mendonça \& Matos, 2005). Para isso, foram pesadas amostras de 5,0 g de solo em triplicata, que foram colocadas em frascos de vidro, e outras três amostras de cada tratamento não foram submetidas à irradiação. A extração do $\mathrm{P}$ foi feita pela adição de $50 \mathrm{~mL}$ de uma solução de $\mathrm{NaHCO}_{3} 0,5 \mathrm{~mol} \mathrm{~L}^{-1}(\mathrm{pH} \mathrm{8,5)}$ e, posteriormente, quantificada pelo método colorimétrico do molibdato-ácido ascórbico. Para a correção da fixação do $\mathrm{P}$ inorgânico durante a extração, foi estimada a taxa de recuperação de uma quantidade conhecida de $\mathrm{P}$ adicionado ao solo juntamente com o extrator $\mathrm{NaHCO}_{3}$. O fator de correção para o cálculo do $\mathrm{P}$ da biomassa foi de 0,40 , considerando que nem todo o $\mathrm{P}$ microbiano foi extraído por esse método (Mendonça \& Matos, 2005).

Os resultados das análises foram submetidos à análise de variância; quando significativos, empregouse o teste de Tukey $(p<0,05)$ para a comparação entre as médias, utilizando o seguinte modelo estatístico para a análise da variância, com respectiva restrição para as épocas de amostragem:

$$
\begin{aligned}
\text { Yijk }=\mu+B i & +A j+\operatorname{erro} a(i, j)+C k+\operatorname{erro~b}(i, k) \\
& +A C j k+\operatorname{erroc}(i, j, k)
\end{aligned}
$$

em que $\mathrm{B}=$ blocos $(\mathrm{i}=1,2,3) ; \mathrm{A}=$ intensidades de pastejo $(\mathrm{j}=1,2,3,4)$; e $\mathrm{C}=$ épocas de amostragem $(\mathrm{k}=$ $1,2,3,4)$.

\section{RESULTADOS E DISCUSSÃO}

O C (C-BM), o N (N-BM) e o P (P-BM) na biomassa microbiana foram influenciados tanto pelas intensidades de pastejo como pela época de amostragem do solo (Figura 2). Enquanto o C-BM e o P-BM (Figura 2a,c) aumentaram da amostragem de maio à de setembro e depois decresceram em novembro, o NBM teve uma tendência de decréscimo ao longo do período de amostragem do solo (maio a novembro). $\mathrm{O}$ C-BM e o P-BM parecem seguir a curva de crescimento da pastagem; o C-BM apresentou certa estabilidade na duas primeiras amostragens (maio e julho), provavelmente pelas temperaturas amenas nesses meses e baixo crescimento da pastagem em relação aos outros meses (Quadro 2), tendo como consequência pouca exsudação radicular; já o P-BM apresentou aumento até o mês com o máximo crescimento médio da pastagem, em setembro. A partir desse período, a pastagem de aveia-preta normalmente inicia seu processo de senescência, resultando em menor biomassa microbiana devido à menor liberação de exsudatos e menor matéria seca da parte aérea (Quadro 2). O decréscimo do N-BM ao longo do período de crescimento da pastagem está relacionado provavelmente com a diminuição da disponibilidade desse nutriente no solo, que era mais alta no início (maio e julho) e igual para todos os tratamentos (Quadro 1), em função da decomposição dos resíduos vegetais da soja e da aplicação de $45 \mathrm{~kg} \mathrm{ha}^{-1}$ de N (como ureia) aos 45 dias após a semeadura da pastagem, respectivamente.

De maneira geral, o P-BM (Figura 2c) apresentou menor variação entre os tratamentos (pressões de pastejo) no início do crescimento da pastagem em relação ao C-BM e N-BM (Figura 2a,b). Isso porque sistemas de integração lavoura-pecuária somente irão promover reduções nos teores de P-BM em intensidades muito elevadas de pastejo, que alterarão negativamente a população microbiana do solo (Souza et al., 2008). A similaridade de incorporação de P na BMS entre os tratamentos no presente trabalho deve-se à adição contínua de adubo fosfatado (em torno de $60 \mathrm{~kg} \mathrm{ha}^{-1}$ ano $^{-1}$ de $\mathrm{P}_{2} \mathrm{O}_{5}$ ), que promoveu aumento do $\mathrm{P}$ lábil (Souza, 2008), e à grande disponibilidade de $\mathrm{C}$ proveniente dos resíduos da soja (Quadro 1) sobre o solo. Segundo Conte et al. (2002), a adição de apenas $20 \mathrm{~kg}$ ha-1 de $\mathrm{P}_{2} \mathrm{O}_{5}$ na semeadura da soja contribuiu para a obtenção de valores de P-BM de 19,2 $\mathrm{mg} \mathrm{dm}^{-3}$ no final do ciclo da soja, contra os $9,4 \mathrm{mg} \mathrm{dm}^{-3}$ da área sem aplicação de $\mathrm{P}$, sendo esses valores menores do que os que foram obtidos no presente trabalho, especialmente a partir da segunda amostragem (Figura 2c). 

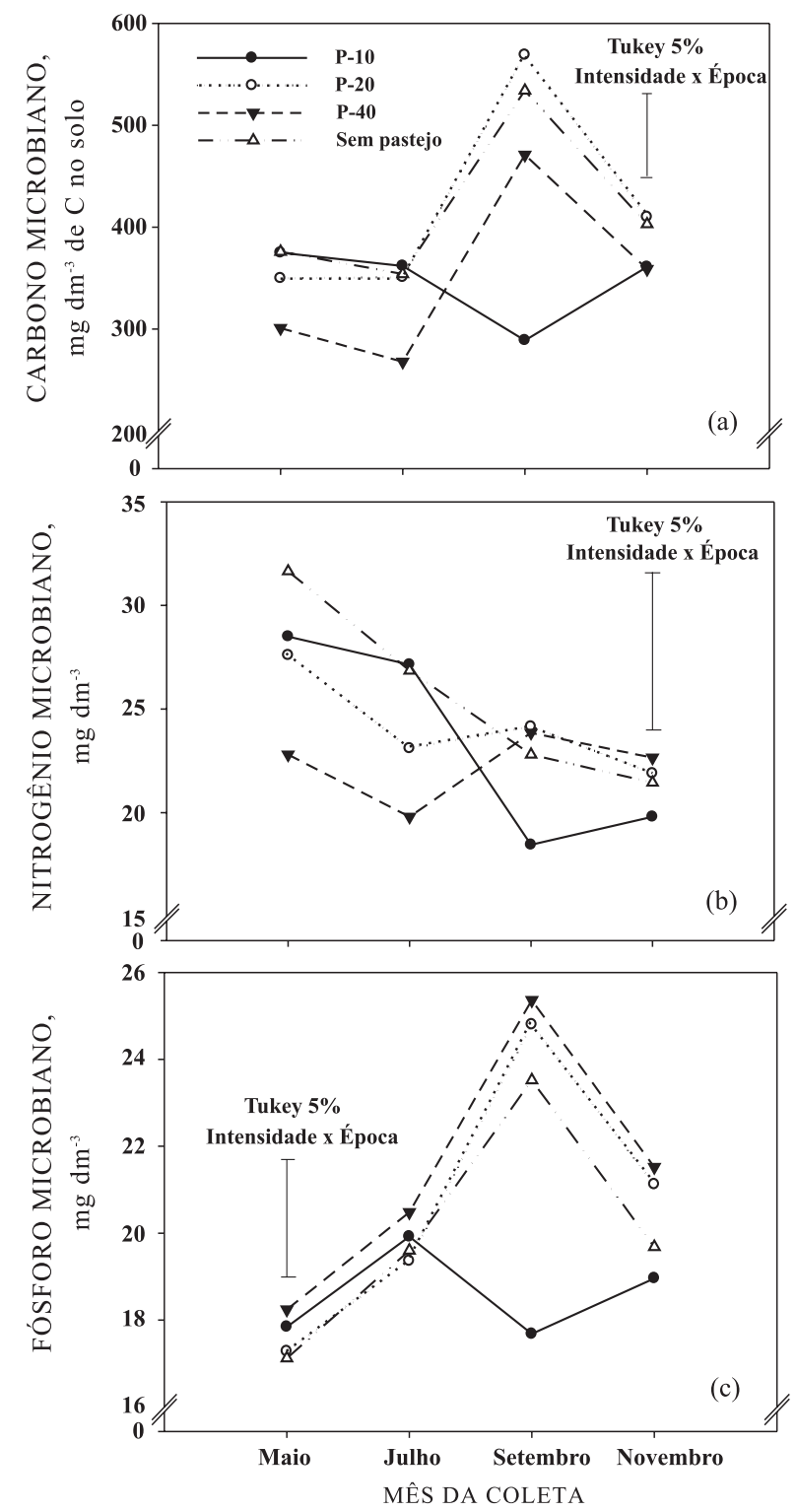

Figura 2. Carbono (a), nitrogênio (b) e fósforo (c) na biomassa microbiana no ciclo de pastejo, na camada de 0 a $10 \mathrm{~cm}$, de um Latossolo Vermelho em função de intensidades de pastejo em sistema de integração lavoura-pecuária sob plantio direto. $\mathrm{P}-10, \mathrm{P}-20$ e $\mathrm{P}-40$ representam as alturas de pastejo de 10, 20 e $40 \mathrm{~cm}$, respectivamente.

A despeito de as quantidades de resíduos da pastagem terem sido variadas entre as épocas de amostragem (Quadro 2), assim como os dejetos advindos dos animais (esterco e urina), e em função das diferentes pressões de pastejo anterior ao cultivo da soja, o C-BM e o P-BM somente se diferenciaram entre as diferentes pressões de pastejo na amostragem de setembro (Figura 2a,c). Essa diferenciação deveuse, muito provavelmente, à ocorrência de um déficit hídrico (estiagem) que ocorreu entre o final de agosto e o dia da amostragem (Figura 1), o qual provocou, na maior intensidade de pastejo $(\mathrm{P} 10 \mathrm{~cm})$, baixo acúmulo de C-BM, N-BM e P-BM (Figura 2a,b,c). O somatório de diversas condições do solo pode ter ampliado a magnitude dos efeitos na biomassa microbiana. A baixa proteção do solo contra a perda de água por evaporação nesse tratamento (Quadro 2), o efeito quase que direto dos raios solares, podendo aumentar a temperatura do solo e diminuir a umidade (Quadro 3), a maior densidade, o menor VTP, Ma, teor de COT e COP (Quadro 1) propiciaram diminuição na biomassa microbiana do solo. Por outro lado, nas áreas com menores intensidades de pastejo, a cobertura do solo evita a perda de água e o aumento da temperatura do solo e favorece o aumento da BMS (Matsuoka et al., 2003). Verifica-se que, em situações sem estresse, mesmo na maior intensidade de pastejo, o sistema de integração lavoura-pecuária consegue manter os teores de nutrientes da BMS em valores iguais aos das menores intensidades de pastejo.

Neste trabalho, os teores de C-BM e P-BM no mês de novembro foram similares aos de maio pelo fato de a pastagem já estar em fase de senescência, com menor liberação de exsudatos; exceção, no entanto, ocorre no P-10, que durante todo o ciclo da pastagem emite perfilhos e raízes em função do pastejo intensivo. No entanto, no momento em que ocorre alguma condição adversa aos microrganismos, como na maior intensidade de pastejo, a resposta é rápida, com diminuição na sua população e, com isso, redução nas quantidades de C-BM, N-BM e P-BM.

Os teores decrescentes de N-BM nas pressões de pastejo SP, P10, P20 e P40, verificados na primeira amostragem (Figura 2b), não se relacionam com a quantidade de $\mathrm{N}$ aplicada na pastagem $\left(45 \mathrm{~kg} \mathrm{ha}^{-1} \mathrm{em}\right.$ todos os tratamentos), nem com a quantidade de resíduos da soja (Quadro 1) e nem com os resíduos remanescentes da pastagem anterior à soja, que foram crescentes (Quadro 2). Devido à constante absorção de nutrientes pela planta, os teores de $\mathrm{N}$ no solo tendem a diminuir. Com isso, o N-BM também segue diminuindo com o tempo, fazendo com que desapareçam as diferenças entre as intensidades de pastejo (Figura 2b), com baixos teores em novembro, variando de 19,8 a $22,7 \mathrm{mg} \mathrm{dm}^{-3}$ de solo para os tratamentos P-10 e SP, respectivamente. No mês de maio, o maior N-BM foi na área sem pastejo, e o menor, em P-40 (Figura 2b). Blankenau et al. (2000) consideram o N-BM um indicador fraco da imobilização de $\mathrm{N}$ adicionado ao solo na forma de fertilizantes, pois apenas 2,9 a $23,8 \%$ do $\mathrm{N}$ perdido do sistema solo-planta foram imobilizados na BMS durante o cultivo do trigo. Hatch et al. (2000) e Vargas et al. (2005) observaram, em solo sob pastagem e plantio direto, respectivamente, aumentos no N-BM apenas em longo prazo. Esses autores argumentam que isso se deve ao efeito acumulativo de resíduo vegetal e consequente aumento de $\mathrm{C}$ orgânico no solo.

O P-BM no presente estudo foi, na média das épocas, de $6,5,7,5,7,7$ e 7,2 \% do $\mathrm{P}$ orgânico (Po) total para as intensidades P-10, P-20, P-40 e SP, respectivamente 
(Souza, 2008). Rheinheimer et al. (2000) obtiveram, para um Latossolo Vermelho distroférrico típico, similar ao do presente estudo, valores de P-BM de até $19 \%$ do Po total. Esse valor é considerado alto, pois, de acordo com Magid et al. (1996), os teores médios encontrados na literatura são de 2 a $5 \%$, apesar de já terem sido encontrados teores de até $20 \%$ do Po total (Qualls \& Richardson, 1995).

Alguns importantes fatores contribuem para o aumento de nutrientes na BMS, sendo ele, porém, mais determinado pelos resíduos disponíveis no solo e em sua superfície. Segundo Tisdall \& Oades (1982), o corte da parte aérea de plantas de azevém promove aumento na exsudação de compostos orgânicos pelas raízes, além de aumento da rizosfera. Dessa forma, quanto maior a presença de raízes, maior deve ser a exsudação de compostos orgânicos, que servirão como fonte de $\mathrm{C}$ e energia à BMS, ocorrendo estímulo ao aumento desta. Com isso, pode-se afirmar que intensidades moderadas de pastejo podem influenciar positivamente tanto a parte aérea como o sistema radicular da pastagem, o que justifica o fato de na intensidade P-20, neste estudo, os teores de nutrientes na BMS serem elevados, assemelhando-se aos verificados na área sem pastejo.

A exemplo do que ocorreu com a BMS, apesar da tendência apresentada em todas as épocas de amostragem, a respiração da BMS (R-BM) somente foi alterada $(p<0,05)$ pelas pressões de pastejo na amostragem de setembro, sendo mais elevada na maior intensidade de pastejo (P-10) (Figura 3), pela ocorrência do déficit hídrico entre o final do mês de agosto e o dia da amostragem (Figura 1), o que acarretou menor umidade no solo (Quadro 3), possivelmente devido à menor quantidade de resíduos vegetais cobrindo o solo (Quadro 2). Na avaliação do mês de julho, a R-BM foi menor, em razão das temperaturas mais baixas, que resultaram em atividade da BMS diminuída pela menor atividade fisiológica da planta e, consequentemente, menor quantidade de exsudatos radiculares (Chen et al., 2006) - fonte de $\mathrm{C}$ prontamente mineralizável para a BMS. É importante, porém, ressaltar que valores baixos nessa ocasião não necessariamente significam condições indesejáveis (D’Andréa, 2001), pois, em longo prazo, alta R-BM significa perdas de C do solo, embora, no curto prazo, possa significar liberação de nutrientes que podem ser absorvidos pelas plantas.

O quociente metabólico $\left(q \mathrm{CO}_{2}\right)$ (Figura 4) seguiu o mesmo comportamento da R-BM ao longo do tempo de amostragem e com valor alto e diferenciado no tratamento P-10 no mês de setembro, pelo efeito do estresse devido aos fatores citados anteriormente. $\mathrm{Na}$ média das épocas de amostragem, a exemplo da RM (Figura 3), não houve variações no $q \mathrm{CO}_{2}$ entre as intensidades de pastejo (Figura 4). Valores muito elevados de $q \mathrm{CO}_{2}$ foram encontrados em condições ambientais estressantes (P-10), nas quais a BMS gasta mais C para sua manutenção. Segundo Souza et al.

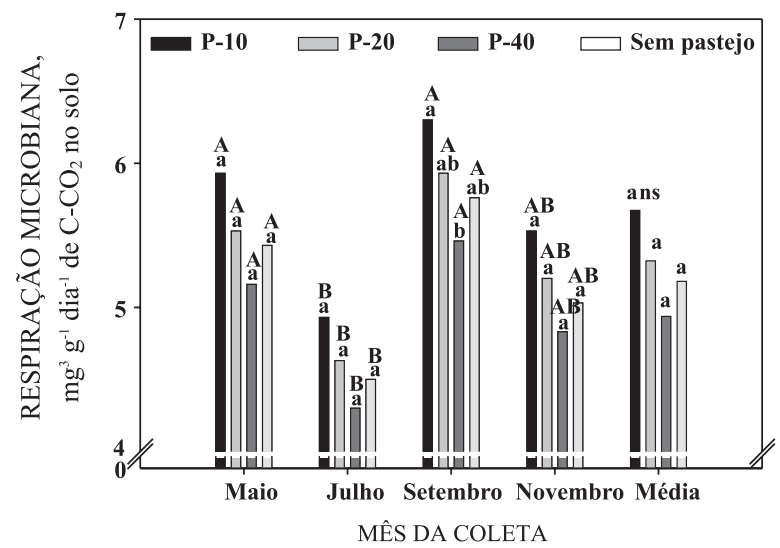

Figura 3. Respiração da biomassa microbiana do solo no ciclo de pastejo, na camada de 0 a $10 \mathrm{~cm}$, de um Latossolo Vermelho em sistema de integração lavoura-pecuária submetido a intensidades de pastejo sob plantio direto. P-10, $\mathrm{P}-20$ e P-40 representam as alturas de 10, 20 e $40 \mathrm{~cm}$, respectivamente. Letras minúsculas comparam as intensidades de pastejo dentro de cada mês de coleta. Letras maiúsculas comparam cada intensidade de pastejo entre os meses de coleta. Letras semelhantes não diferem entre si pelo teste de Tukey a $5 \%$. ns: não significativo.

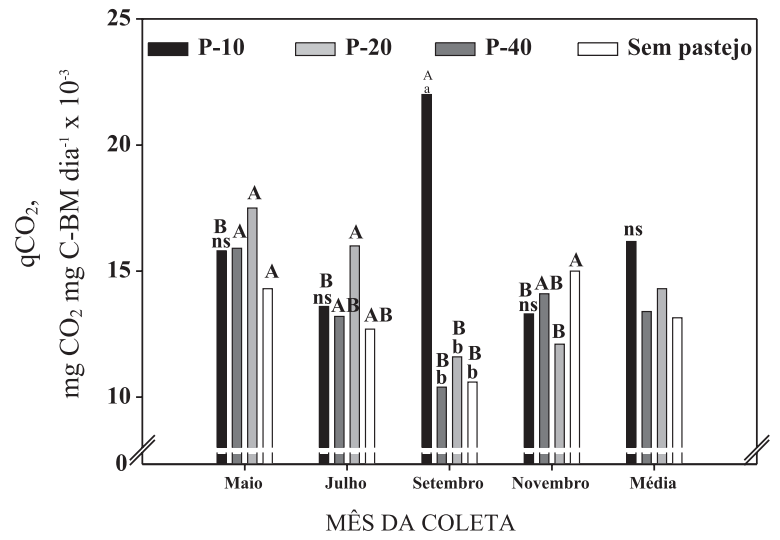

Figura 4. Quociente metabólico $\left(q \mathrm{CO}_{2}\right)$ no ciclo de pastejo, na camada de 0 a $10 \mathrm{~cm}$, de um Latossolo Vermelho em sistema de integração lavourapecuária submetido a intensidades de pastejo sob plantio direto. $\mathrm{P}-10, \mathrm{P}-20$ e $\mathrm{P}-40$ representam as alturas de 10,20 e $40 \mathrm{~cm}$, respectivamente. Letras minúsculas comparam as intensidades de pastejo dentro de cada mês de coleta. Letras maiúsculas comparam cada intensidade de pastejo entre os meses de coleta. Letras semelhantes não diferem entre si pelo teste de Tukey a 5 \%. ns: não significativo.

(2006b), à medida que a BMS torna-se mais eficiente, menos $\mathrm{C}$ é perdido como $\mathrm{CO}_{2}$ pela respiração e uma fração significativa é incorporada ao tecido microbiano; com isso, solos com baixo $q \mathrm{CO}_{2}$ estariam mais próximos 
do estado de equilíbrio. No entanto, as interpretações do quociente metabólico devem ser feitas com critério, visto que somente 15 a $30 \%$ da BMS do solo é catabolicamente ativa (Mac Donald, 1986), e o restante dos microrganismos do solo está na forma inativa ou latente, tendo baixa atividade.

A exemplo da R-BM e do $q \mathrm{CO}_{2}$, a relação $\mathrm{C} / \mathrm{N}$ (Figura 5a) não teve influência das intensidades de pastejo nos meses de maio, junho e novembro; já no mês de setembro esse efeito ocorreu. Nas duas coletas iniciais, havia quantidades significativas de $\mathrm{N}$ no solo (Quadro 1), primeiramente devido aos resíduos da cultura da soja e, posteriormente, em função da adubação nitrogenada em cobertura na pastagem. Isso causa diminuição da relação $\mathrm{C} / \mathrm{N}$ do material vegetal, que é mais rapidamente decomposto pelos microrganismos; por conseguinte, parte dos nutrientes dos resíduos é liberada ao solo e parte é incorporada ao tecido microbiano. A maior relação $\mathrm{C} / \mathrm{N}$, especialmente no
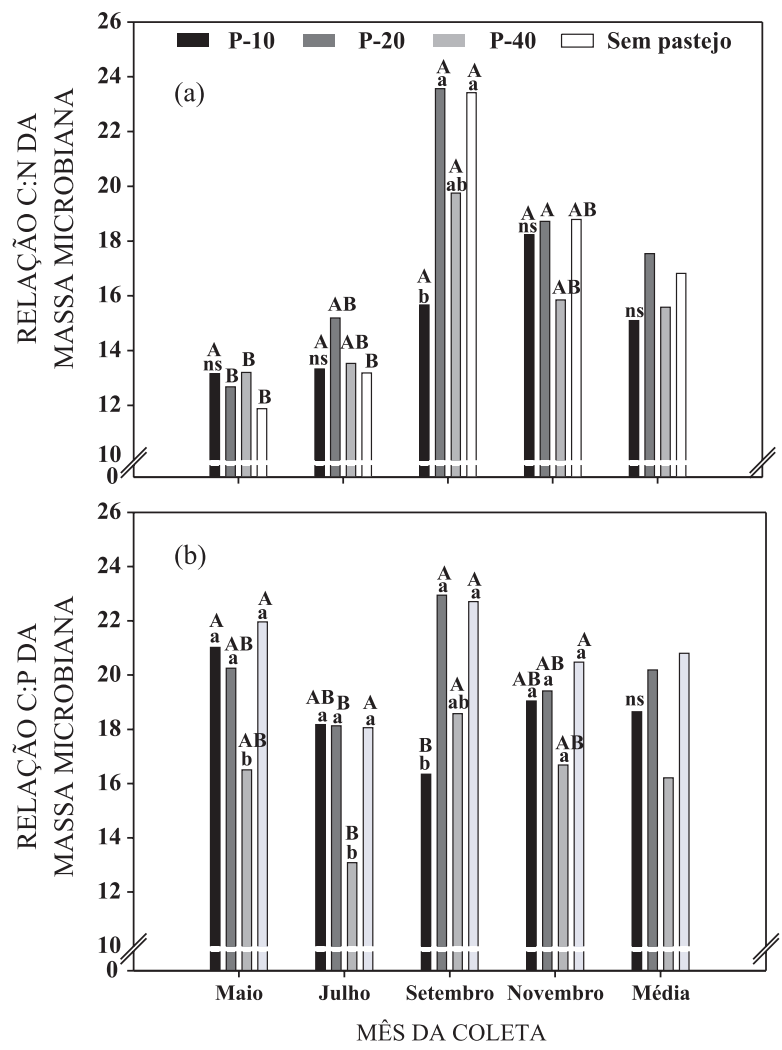

Figura 5. Relação C:N (a) e C:P (b) da biomassa microbiana no ciclo de pastejo, na camada de 0 a $10 \mathrm{~cm}$, de um Latossolo Vermelho em sistema de integração lavoura-pecuária submetido a intensidades de pastejo sob plantio direto. P-10, P-20 e P-40 representam as alturas de 10,20 e $40 \mathrm{~cm}$, respectivamente. Letras minúsculas comparam as intensidades de pastejo dentro de cada mês de coleta. Letras maiúsculas comparam cada intensidade de pastejo entre os meses de coleta. Letras semelhantes não diferem entre si pelo teste de Tukey a $5 \%$. ns: não significativo. mês de setembro, deve-se à absorção de $\mathrm{N}$ pelas plantas e posterior ingestão pelos animais e, ainda, perdas no sistema. Quando ocorre menor disponibilidade de $\mathrm{N}$ no solo, a BMS torna-se mais eficiente em seu aproveitamento, como também observado por Gijsman et al. (1997) em sistemas de gramíneas puras, em relação à presença de leguminosas no sistema.

A relação $\mathrm{C} / \mathrm{P}$ (Figura 5b) não segue a mesma tendência do C-BM e do N-BM (Figura 2a,b), pois apresenta variação entre as intensidades de pastejo e as épocas de amostragem. Em todas as avaliações, houve influência das intensidades de pastejo sobre a relação $\mathrm{C} / \mathrm{P}$, que pode ser comparada à variação do $\mathrm{P}$ BM (Figura 2c) e também relacionada com o C-BM (Figura 2a). Para Gijsman et al. (1997), a relação C/ $\mathrm{P}$ é influenciada pela utilização de leguminosas no sistema. Entretanto, no presente estudo, o que parece ter mais influenciado essa relação foi o C-BM e o alto teor de P disponível no solo (Souza, 2008), tal como indicado por Chauhan et al. (1981).

Os estoques (média das épocas) de C-BM (Figura 6a) e de N-BM (Figura 6b) não diferiram $(p<0,05)$ entre as intensidades de pastejo, mesmo variando de 487 a
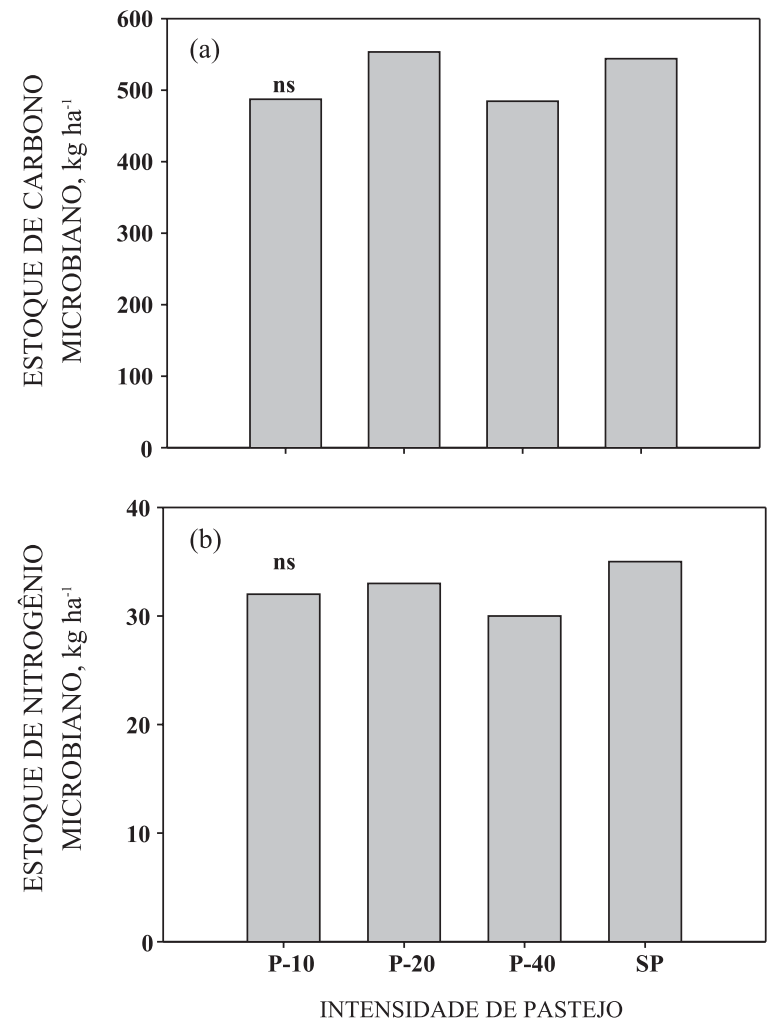

Figura 6. Estoque de carbono (a) e nitrogênio (b) médio na biomassa microbiana, na camada de 0 a $10 \mathrm{~cm}$, de um Latossolo Vermelho em função de intensidades de pastejo em sistema de integração lavoura-pecuária sob plantio direto. $\mathrm{P}-10, \mathrm{P}-20, \mathrm{P}-40$ e SP representam as alturas de $10,20,40 \mathrm{~cm}$ e sem pastejo, respectivamente. $\mathrm{ns}$ : não significativo. 
$554 \mathrm{~kg} \mathrm{ha}^{-1}$ de $\mathrm{C}$ e de 30 a $35 \mathrm{~kg} \mathrm{ha}^{-1}$ de $\mathrm{N}$ para as áreas P-10 e P-20, respectivamente. Os altos estoques de C-BM demonstram que a BMS representa um importante compartimento lábil da matéria orgânica do solo, o qual é essencial à ciclagem de nutrientes e à dinâmica das demais frações da matéria orgânica do solo. Os estoques de N-BM mostram que a BMS representa um importante compartimento do estoque de $\mathrm{N}$ no solo. Com isso, parte desse $\mathrm{N}$ pode ser liberada após a morte dos microrganismos e, assim, ser disponibilizada para as plantas. Ao mesmo tempo, em sistemas de culturas que depositem no solo resíduo de baixa relação $\mathrm{C} / \mathrm{N}$ e no solo em que os teores de $\mathrm{N}$ sejam relativamente baixos, o $\mathrm{N}$ presente no resíduo pode ser utilizado pela BMS e, consequentemente, ficar indisponível para as plantas.

\section{CONCLUSÕES}

1. Sistemas de integração lavoura-pecuária em plantio direto submetidos a intensidades moderadas de pastejo conseguem manter o nível de qualidade biológica do solo, sendo similar ao sistema plantio direto sem a entrada de animais.

2. Os teores de $\mathrm{C}$, de $\mathrm{N}$ e de $\mathrm{P}$ microbiano variam em função da época de desenvolvimento da pastagem; não há efeito negativo da inserção do animal no sistema quando sob intensidades moderadas de pastejo.

3. Alta intensidade de pastejo (baixa altura da pastagem, $10 \mathrm{~cm}$ ) pode provocar redução no $\mathrm{C}$, no $\mathrm{N}$ e no $\mathrm{P}$ da biomassa microbiana e aumento na respiração microbiana do solo sob condições de estresse hídrico.

\section{LITERATURA CITADA}

ALEF, K. \& NANNIPIERI, P. Methods in applied soil microbiology and brochemistry. London, Academic Press, 1995. 576p.

ANDERSON, J.P.E. \& DOMSCH, K.H. The metabolic quotient $\left(\mathrm{qCO}_{2}\right)$ as a specific activity parameter to asses the effects of environmental conditions, such as $\mathrm{pH}$, on the microbial biomass of forest soils. Soil Biol. Biochem., 25:393-395, 1993.

BALOTA, E.L.; COLOZZI-FILHO, A.; ANDRADE, D.S. \& HUNGRIA, M. Biomassa microbiana e sua atividade em solos sob diferentes sistemas de preparo e sucessão de culturas. R. Bras. Ci. Solo, 22:641-649, 1998.

BIRCHAM, J.S. Herbage growth and utilization under continuous stocking management. Edinburgh, University of Edinburgh, 1981. 384p. (Tese de Doutorado)

BLANKENAU, K.; OLFS, H.W. \& KUHLMANN, H. Effect of microbial nitrogen immobilization during the growth period on the availability of nitrogen fertilizer for winter cereals. Biol. Fert. Soils, 32:157-165, 2000.
CATTELAN, A.J. \& VIDOR, C. Flutuações na biomassa, atividade e população microbiana do solo, em função de variações ambientais. R. Bras. Ci. Solo, 14:133-142, 1990.

CHAUHAN, B.S.; STEWART, J.W.B. \& PAUL, E.A. Effect of labile inorganic phosphate status and organic carbon additions on the microbial uptake of phosphorus in soils. Canadian J. Soil Sci., 61:373-385, 1981.

CHEN, Y.; LEE, P.; LEE, G.; MARIKO, S. \& OIKAWA, T. Simulating root responses to grazing of a Mongolian grassland ecosystem. Plant Ecol., 183:265-275, 2006.

COMISSÃO DE QUÍMICA E FERTILIDADE DO SOLO CQFSRS/SC. Recomendações de adubação e calagem para os Estados do Rio Grande do Sul e de Santa Catarina. 10.ed. Porto Alegre, Sociedade Brasileira de Ciência do Solo - Núcleo Regional Sul, 2004. 400p.

CONCEIÇÃO, P.C.; AMADO, T.J.C.; MIELNICZUK, J. \& SPAGNOLLO, E. Qualidade do solo em sistemas de manejo avaliada pela dinâmica da matéria orgânica e atributos relacionados. R. Bras. Ci. Solo, 29:777-788, 2005.

CONTE, E.; ANGHINONI, I. \& RHEINHEIMER, D.S. Fósforo da biomassa microbiana e atividade de fosfatase ácida após aplicação de fosfato em solo no sistema plantio direto. R. Bras. Ci. Solo, 26:925-930, 2002.

CONTE, O. Atributos físicos de solo e demanda de tração em semeadura direta de soja, com diferentes pressões de pastejo em sistema de integração lavoura-pecuária. Porto Alegre, Universidade Federal do Rio Grande do Sul, 2007. 91p. (Tese de Mestrado)

D’ANDRÉA, A.F. Atributos indicadores da qualidade do solo em sistemas de manejo no sul de Goiás. Lavras, Universidade Federal de Lavras, 2001. 106p. (Tese de Mestrado)

ELLERT, B.H. \& BETTANY, J.R. Calculation of organic matter and nutrients stored in soils under contrasting management regimes. Canadian J. Soil Sci., 75:529-538, 1995.

EMPRESA BRASILEIRA DE PESQUISA AGROPECUÁRIA EMBRAPA. Centro Nacional de Pesquisa de Solos. Sistema brasileiro de classificação de solos. Rio de Janeiro, 2006. 306p.

GIJSMAN, A.J.; OBERSON, A.; FRIESEN, D.K.; SANZ, J.I. \& THOMAS, R.J. Nutrient cycling through microbial biomass under rice-pasture rotations replacing native savanna. Soil Biol. Biochem., 29:1433-1441, 1997.

HATCH, D.J.; LOVELL, R.D.; ANTIL, R.S.; JARVIS, S.C. \& OWEN, P.M. Nitrogen mineralization and microbial activity in permanent pastures amended with nitrogen fertilizer or dung. Biol. Fert. Soils, 30:288-293, 2000.

HAYNES, R.J. \& WILLIAMS, P.H. Influence of stock camping behavior on the soil microbiological and biochemical properties of grazed pastoral soils. Biol. Fert. Soils, 28:253258,1999

ISLAM, K.R. \& WEIL, R.R. Microwave irradiation of soil for routine measurement of microbial biomass carbon. Biol. Fert. Soils, 27:408-416, 1998.

Mac DONALD, R.M. Extraction of microorganisms from soil. Biol. Agric. Hortic., 3:361-365, 1986. 
MAGID, J.; TIESSEN, H. \& CONDRON, L.M. Dynamics of organic phosphorus in soils under natural and agricultural ecosystems. In: PICCOLO, A., ed. Humic substances. Amsterdam, Elsevier, 1996. p.429-466.

MATSUOKA, M.; MENDES, I.C. \& LOUREIRO, M.F. Biomassa microbiana e atividade enzimática em solos sob vegetação nativa e sistemas agrícolas anuais e perenes na região de Primavera do Leste (MT). R. Bras. Ci. Solo, 27:425-433, 2003.

MENDONÇA, E.S. \& MATOS, E.S. Matéria orgânica do solo: métodos de análises. Viçosa, MG, Universidade Federal de Viçosa, 2005. 107p.

QUALLS, R.G. \& RICHARDSON, C. Forms of soil phosphorus along a nutrient enrichment gradient in the Northern Everglades. Soil Sci., 160:183-198, 1995.

REZENDE, L.A.; ASSIS, L.C. \& NAHAS, E. Carbon, nitrogen and phosphorus mineralization in two soils amended with distillery yeast. Biores. Technol., 94:159-167, 2004.

RHEINHEIMER, D.S.; ANGHINONI, I. \& CONTE, E. Fósforo da biomassa microbiana em solos sob diferentes sistemas de manejo. R. Bras. Ci. Solo, 24:589-597, 2000.

SOUZA, E.D. Evolução da matéria orgânica, do fósforo e da agregação em sistema de integração agricultura-pecuária em plantio direto, submetido a intensidades de pastejo. Porto Alegre, Universidade Federal do Rio Grande do Sul, 2008.162p. (Tese de Doutorado)
SOUZA, E.D.; COSTA, S.E.V.G.A.; LIMA, C.V.S.; ANGHINONI, I.; EGON JOSÉ MEURER, J.E. \& CARVALHO, P.C.F. Carbono orgânico e fósforo microbiano em sistemas de integração agricultura-pecuária submetidos a intensidades de pastejo em plantio direto. R. Bras. Ci. Solo, 32:1273$1282,2008$.

SOUZA, E.D.; CARNEIRO, M.A.C.; PAULINO, H.B.; SILVA, C.A. \& BUZETTI, S. Frações do carbono orgânico, biomassa e atividade microbiana em um Latossolo Vermelho sob Cerrado submetido a diferentes sistemas de manejos e usos do solo. Acta Sci. Agron., 28:323-329, 2006a.

SOUZA, E.D.; CARNEIRO, M.A.C.; PAULINO, H.B.; SILVA, C.A. \& BUZETTI, S. Alterações nas frações do carbono em um Neossolo quartzarênico submetido a diferentes sistemas de uso do solo. Acta Sci. Agron., 28:305-311, 2006b.

TEDESCO, M.J.; VOLKWEISS, S.J. \& BOHMEN, H. Análise de solo, plantas e outros materiais. 2.ed. Porto Alegre, Universidade Federal do Rio Grande do Sul, 1995. 174p. (Boletim Técnico, 5)

TISDALL, J.M. \& OADES, J.M. Organic matter and waterstable aggregates in soil. J. Soil Sci., 33:141-163, 1982.

VARGAS, L.K.; SELBACH, P.A. \& SÁ, E.L.S. Imobilização de nitrogênio em solo cultivado com milho em sucessão à aveia-preta nos sistemas plantio direto e convencional. Ci. Rural, 35:76-83, 2005. 